\title{
Effects of Agricultural Activities on the Environment
}

\begin{abstract}
ADRIAN TUREK RAHOVEANU*
University of Agronomic Sciences and Veterinary Medicine of Bucharest, 59 Marasti Blvd, 011464, Bucharest, Romania

With the development of intensive farming through the use of fertilizers, pesticides, ithas become increasingly polluting. This is why they are pushing for the return of sustainable agriculture. Sustainable agriculture has as major objectives the optimization of productivity, while preserving the basic natural resources. This means that in agricultural production systems, it is imperative to maintain a balance between inputs and outputs, between investments and benefits, while ensuring the protection of the environment and the promotion of a sustainable economy as a whole. Due to intensive farming, using pesticides, chemical fertilizers, or residues from zootechnical activities, soil is the main affected. Most soils are losing their nutrients and organic matter in a higher proportion than the process of their regeneration, which leads to their depletion, resulting in irreversible degradation. Soil pollution means any action thatcauses the disruption of normal soil functioning as a support and living environment within natural ecosystems.
\end{abstract}

Keywords: sustainable agriculture, environmental protection, soil pollution, sustainable activities

In order to meet the growing need for food the consumer society has demanded that they be obtained on land areas limited in size and in qualitative regression. It is well known that plant nutrition is one of the most important factors to control the productivity and quality of the products obtained. The rate of nutrients in the soil affects the quality of the yields obtained.

As a result, agricultural producers resort to activities such as soil fertilization, pest control, irrigation to make the production process more efficient. Among these activities, fertilization remains a priority at all times.

Existing studies have shown that excessive use of basic chemical fertilizers of phosphorus and nitrogen in agriculture is by no means negligible and results in a large number of environmental problems, with agriculture altering the appearance of the environment (Alloway \& Ayres, 1997; Hart, etal., 2004; Gardner \& Vogel, 2005; Serpil, 2012). Used for a long time, chemical fertilizers can stop recycling organic substances from cultivated soils, threatening their fertility (Shaviv, \& Mikkelsen, 1993; Onder, et al., 2011; Schmidt, et al., 2017). Increasing the amount of chemical fertilizer increasingly reduces the organic components and humus in the soil. This has the effect of damaging the soil structure, thus contributing to the decline of the clay-humic absorption complex in the soil. Existing research (Bock \& Hergert, 1991; Spalding \& Exner, 1993; Boyd \& Massaut, 1999; Almasri \& Kaluarachchi, 2004; Mahvi, et al., 2005; Lerner, \& Harris, 2009; Neagu, 2013) have shown that abusive or uncontrolled use of chemical fertilizers produces groundwater and surface water pollution, with the main negative effect being eutrophication that induces a decrease in the biodiversity of aquatic ecosystems.

To destroy organisms that are harmful to crops, man has created and used chemicals called pesticides, insecticides, herbicides, etc. The residues of many of these chemicals enter the environment, pollute water, air, soil, as well as directly or indirectly, affecting the quality of food. The vast majority of pesticides fall into the group of substances with high or medium toxicity and the risk from the consumption of the treated products is obvious. This potential risk becomes real only to the extent that the treatments are made uncontrolled, incorrectly, when products containing residual amounts of chemicals reach certain limits.
At the same time, there are specialists who have shown that zootechnical activities affect the environment by animal manure residues from animal manure and by separate sewage sludge from zootechnics. (Lake, et al., 1984; Singh \& Agrawal, 2008; Shehrawat, et al., 2015; Ungureanu, et al., 2017).

Therefore sustainable agriculture is the focus of many experts worldwide (Arsic et al., 2013; Mihalache, et al., 2015; Rusu, et al., 2015). In this context, there appeared to be the need to find ways and optimal solutions for combining the economic progress with the preservation of the quality of the natural resources, these being the basis for supporting the agriculture and, implicitly, the quality of life (Sarb, et al., 2013; Mocuta, 2016; Mocuta, 2017). From this perspective, the concept of sustainable agriculture emerged, aiming at achieving and maintaining a balance between the need to preserve the material values of the rural space and the changes caused by the modernization of this sector.

\section{Chemical fertilizers - potential source of water and soil pollution}

Intensive agriculture practiced in all countries of the world involves the use of chemical fertilizers to increase the productivity of crop plants. This process aims to restore to the soil the equivalent of the quantities of nutrients extracted from it by the plants. The most important and most commonly used are nitrogen fertilizers (ammonium, calcium and potassium nitrates), sulfur fertilizers (ammonium sulfate and superphosphate) and potassium.

Between 1992 and 2016, the area of land on which chemical fertilizers based on nitrogen were applied (fig. 1) holds the largest share (59.3\%), followed by surfaces treated with fertilizers based on phosphorus $(32.5 \%)$ and on the basis of potassium (8.2\%).

In terms of the total amount of chemical fertilizers used (fig. 2), nitrogen fertilizers have the highest share in total plant protection products used $(67.0 \%)$, followed by phosphorus fertilizers $(27.3 \%)$ and potassium-based fertilizers (5.7\%).

The average amount of chemical fertilizer unitused (fig. 3 ) is directly proportional to the total amount of fertilizer used: nitrogen fertilizer ( $70.7 \mathrm{~kg} /$ ha active substance) followed by phosphorus fertilizer ( $52.5 \mathrm{~kg} / \mathrm{ha}$ ) and potassium-based fertilizers ( $44.7 \mathrm{~kg} / \mathrm{ha}$ ).

\footnotetext{
*email: aditurek@yahoo.com
} 


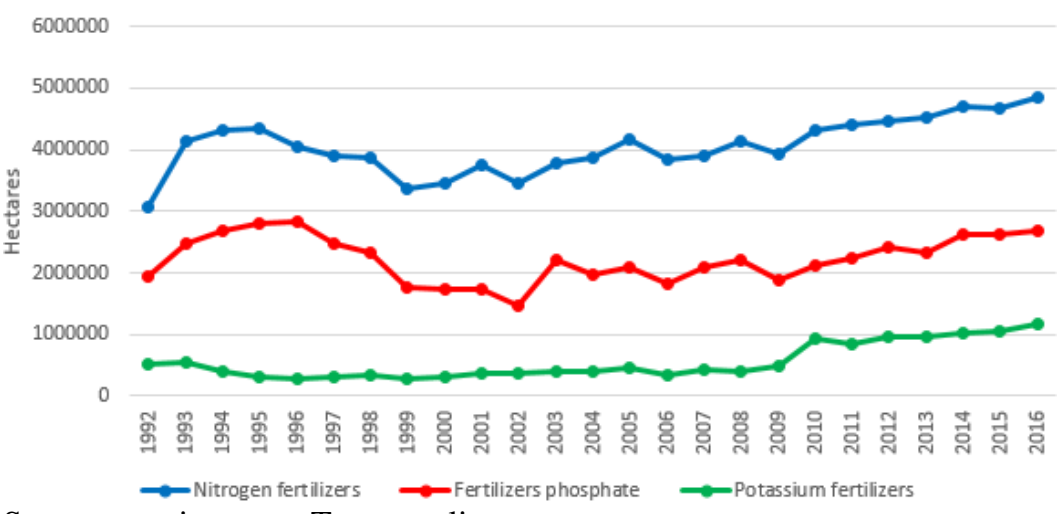

Sursa: www.insse.ro - Tempo online

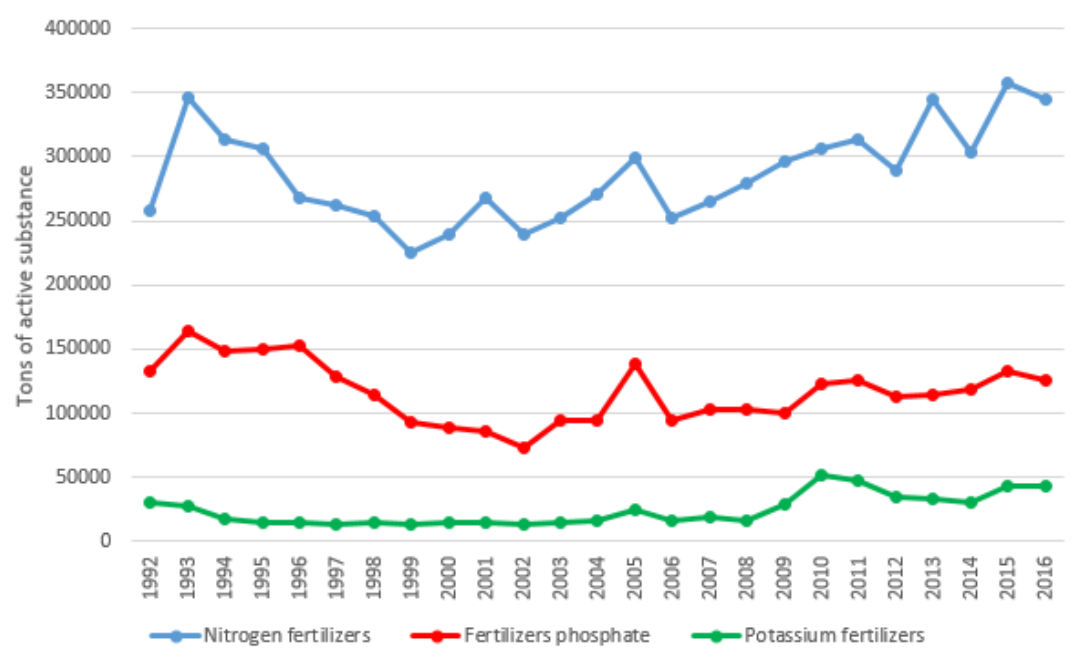

Sursa: www.insse.ro - Tempo online

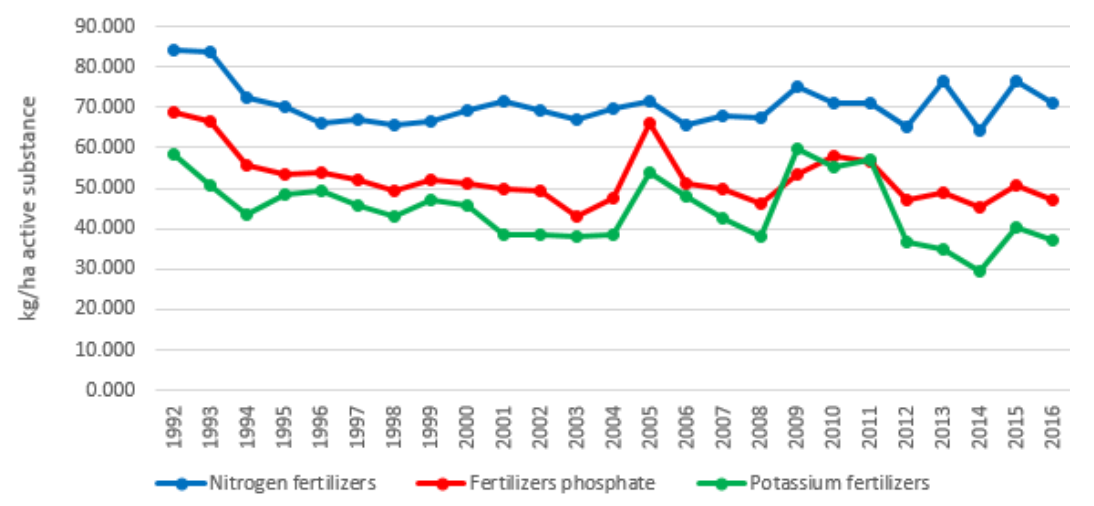

Fig. 1 The surface of the land on which chemical fertilizers were applied

Fig. 2 Total amount of chemical fertilizers used in agriculture
Fig. 3 Average amount of chemical fertilizers used in agriculture
Sursa: www.insse.ro - Tempo online

The pollutant effect is determined by the excessive amounts used, well above what is required, repeatedly used over the years, by their residual effect, and secondary to the introduction into the soil of toxic contaminants contained in fertilizers.

The pollutant effects are due to excess nitrate due to superfertilization with nitrogen fertilizers, which accumulates in soil. Research has shown that nitrates usually accumulate in green leaves (lettuce, spinach) and once consumed such vegetables can endanger the health of consumers. Nitrates in the human intestine turn into nitrosamines, which are powerful carcinogens.

Of the total amount of fertilizer applied on an agricultural surface, in the vegetal mass is found $50 \%$; the rest remains in the ground or is trained in groundwater and surface waters. By means of links of the trophic chains azotates in the vegetal mass are taken over by animals and humans. Through metabolic processes, nitrates are converted into nitrites that have a high affinity to hemoglobin, together with which form methemoglobin, a stable product that drastically reduces tissue oxygenation capacity. Azotates usually arrive through the trophic chain from the fodder plants into milk, the main food of the children.

The main effect of nitrate pollution of surface water is eutrophication. Eutrophication of surface waters (sweet or marine) is characterized by the accelerated growth of algae and other aquatic plants due to the increased content of nitrogen and phosphorus compounds in water. As a result of this process, the balance of aquatic organisms deteriorates, thus diminishing the quality of the water.

Among the negative effects induced by high concentrations of nutrients in water can be remembered:

-The explosion of algae development, which can have toxic effects, affecting human and animal health;

-Excessive growth of aquatic plants that can lead to a decrease in the amount of oxygen in water resulting in the death of fish;

-Excessive weed growth that can lead to drainage prevention and may influence animal welfare;

-Diminishing the clarity of the water;

-LOSS of biodiversity;

-Diminishing economic value and water utilization (example for fisheries and tourism); 
-Cost increases in water treatment plants caused by the need to remove algae, odors and toxins.

In conclusion, the main effect of nitrate pollution of groundwater is the decrease in drinking water. By boiling, nitrate-induced medical problems are not eliminated, but potentiated due to their concentration by evaporation of water.

\section{Pollution of pesticides and their residues}

Pesticides are one of the factors that make it possible to produce an adequate amount of food of plant and animal origin for the growing population, under the conditions of limiting the crop areas.

Choosing the right form of use of the preparation influences both the efficacy of treatment and the degree of environmental pollution. Pesticides are applied in various forms, such as powders, powders, granules, capsules, solutions, suspensions, aerosols, gases, vapors, etc. The choice of form of use must be dictated by the particularities of the pest to be controlled and, on the other hand, by the economic and technical considerations regarding the possibility of applying the given preparation.

During the period 1992-2016, the area treated with herbicides (fig. 4) holds the largest share in the area treated with plant protection products (47.3\%), followed by the surface treated with fungicides (27.4\%) and insecticides (25.3\%).

In terms of the quantity used (fig. 5 and fig. 6), during the analyzed period, the herbicides have the highest share in the total plant protection products used $(45.8 \%)$, followed by fungicides (37.6\%) and insecticides (16.6\%).

Despite all the important advantages of using pesticides in agriculture, their widespread use in high and repeated doses causes many ecological inconveniences. Contamination of soils and vegetation with pesticides has important consequences on species and biocenosis.

Soil pollution with pesticides plays an important role. Soil can be contaminated either by pesticide storage after spraying or by directpesticide treatment. Modern pesticides are mostly organic synthesis substances.

Their application causes a series of changes in the ecosystems in which they were introduced, among which they are remembered:

-They exhibit a very high toxicity spectrum for animal and plant organisms;

- Have a low degree of selectivity and are often used against populations and not against an individual;

-Their effect does not depend on density, although their application takes into account the density;

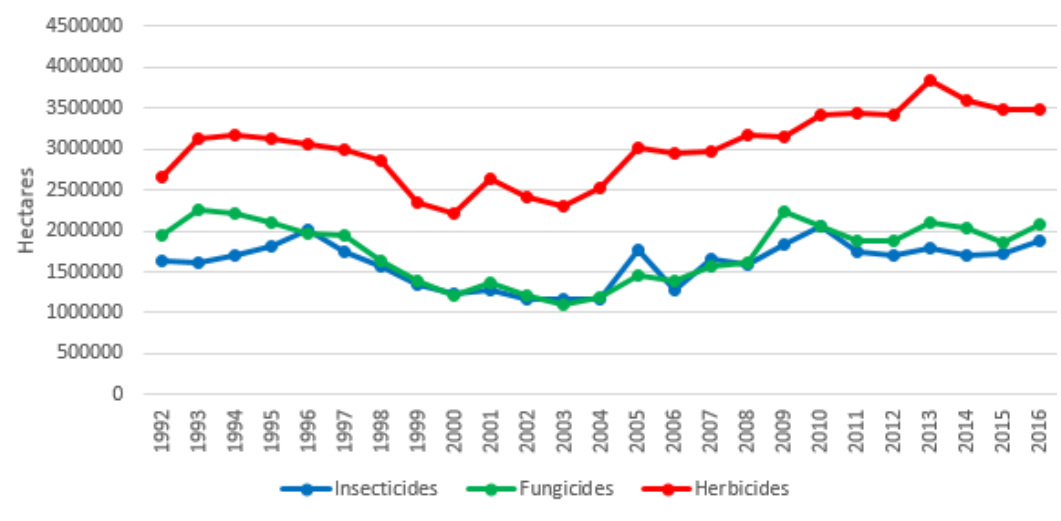

Sursa: www.insse.ro - Tempo online

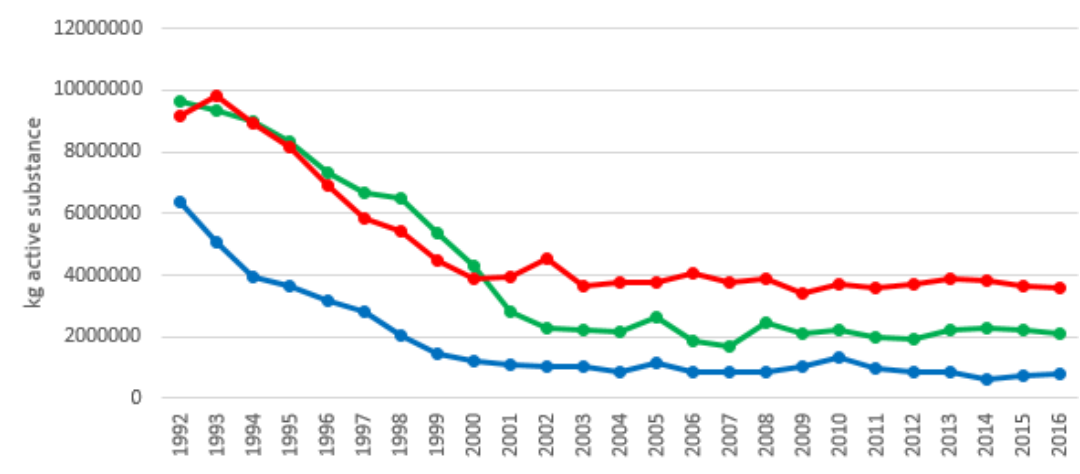

Sursa: www.insse.ro - Tempo online

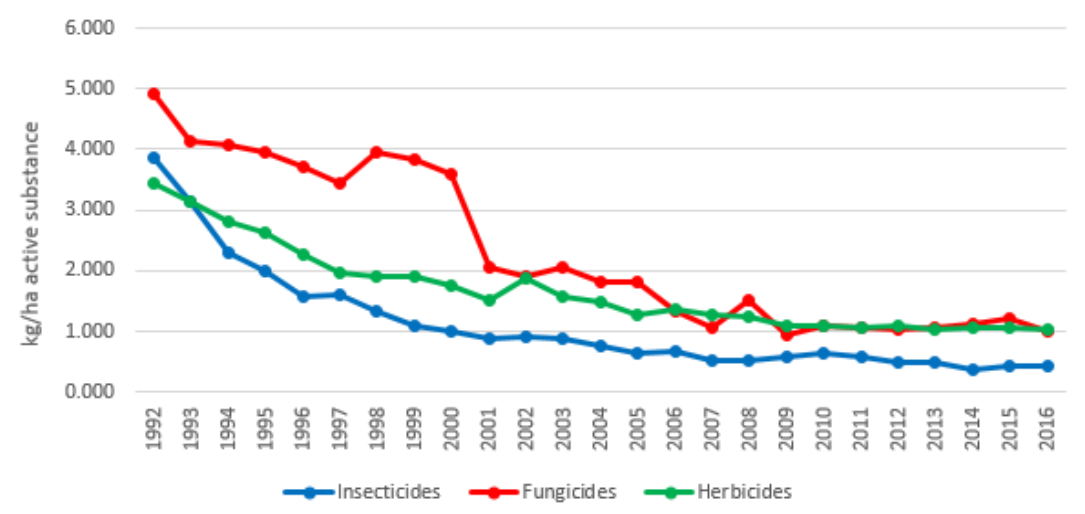

Sursa: www.insse.ro - Tempo online
Fig. 4 The surface of the land on which pesticides have been applied

Fig. 5 The total amount of pesticides applied in agriculture

Fig. 6 . The average amount of pesticides used in agriculture 
-Many of them have a high degree of persistence in soil that may be in the order of months or even years;

-Part of the pesticides disperse very distantly and are incorporated into biomass, surface water or soil;

-Through their biological action, destroy not only the target organisms but also useful ones;

-Persistence in the environment, the accumulation of some of them and their penetration into trophic chains.

Direct effects of pesticide treatments cause the deaths of a large number of individuals in animal and plant populations in treated areas.

Pesticides are highly toxic and can degrade soil biocenoses. Itis known that pesticides in the soil can harm the fauna that contributes to the incorporation of organic matter into the soil. Of these, earthworms play a key role in ensuring soil fertility.

The negative consequences of the application of pesticides are especially the destruction of useful fauna. Here we must first of all mention the natural enemies of plant pests, as well as insects and especially bees, economically important. Bees represent $90 \%$ of the total number of pollinating insects. Among the most common causes of bee poison are: application of pesticides during the flowering of cultivated plants. The consequence of destroying useful insects is the rapid increase in the number of pests, which requires an intensification of the chemical protection of plants. This causes even greater disturbances in the biological balance of nature, as well as increased environmental pollution.

Spraying insecticides from planes above forests can cause strong poisoning especially in forest fauna.

Being toxic to weeds, diseases and pests, pesticides pose a risk to humans, domestic animals, game and birds. For this purpose various processes are used, such as: incorporating activated carbon in the soil; administration of adjuvants in the soil; products that retain or degrade pesticides; plant cultivation (corn, sorghum) that have the ability to clean soil of atrazine by organic absorption; Combating diseases and pests as a measure to prevent soil pollution with pesticides.

Due to the high risks it is recommended to use pesticides that comply with the following rules: to use the least toxic products; avoid the introduction into the ecosystem of hard bio-degradable pesticides, of those with high remanence; avoiding the use products that easily reach groundwater; are not accepted products that penetrate easily into the plant - animal - human food chain.

A safe way to achieve this is to introduce Integrated Protection (Integrated Management), which based on: combining agrotechnical, physical, biological, chemical methods; applying measures to combat only when economically justified.

If in the past we wanted the eradication of pests to the last specimen, in integrated management, the concept is abandoned. In present is considered as, pathogens and weeds produce harvest losses only when they have a certain density. That is why it is recommended to use the economic threshold of harm before using the pesticides to determine exactly the quantity of pesticides needed.

Taking into account the benefits of pesticides in combating different pests or pathogens of plants, animals and humans, but at the same time the negative effects as a local and global pollutant, with profound consequences on ecosystems and human health, the problem of attitude towards pesticides is complex.

Their production and use can not be stopped, but severe measures are required to ban the use of these substances with high toxicity and high retention. The use of selective pesticides in integrated combat is an effective measure to reduce environmental pollution.

\section{Soil pollution with zootechnical waste}

Excessive livestock manure as a fertilizer affects the properties of soils. They may contain biostimulators, urea, drugs, pathogens, which cause chemical and biological soil pollution, decrease permeability, and can spread to phreatic waters, turning them into outbreaks of chemicals, viruses, etc. Also from zootechnics results substances for cleaning the stables, which contributes to the pollution of soils and waters.

In order for the manure to be used in agriculture, its content of heavy metals and viruses is analyzed, especially as some viruses, such as enteric pests, can resist for 9 months. By fermentation for 3 months in summer, or 4 months in the winter, pig manure, free from pathogens is transformed into a valuable fertilizer called compost. The livestock sludge can be stored for 6 months before being used for grassland fertilization, or 3 months for the field.

Separate sludges from zootechnical wastewater contain organic substances. They can only be applied in agriculture if the heavy and nonmetallic metal contents are below the limits allowed by the standards. Some crops such as potatoes, carrots can withstand higher content of heavy metals, but others such as salad does not support. Pathogens in sludge can persist in soil and vegetables. The sludge is applied one month before sowing to allow the soil to retain some compounds. In the pastures, the animals are brought after the sludge has been washed from the rain on the leaves and grass. Plants are influenced differently by the applied sludge.

The application of livestock manure in excessive doses, which exceed the requirements of plants, can adversely affect the fertility of the soil by its negative influence on physical state, permeability, water retention capacity, oxygen content. In the case of the application of manure in large quantities, contents in soil-soluble salts become excessive and can prevent the grow th of the plants or they can be leached into the groundwater.

\section{Conclusions}

Agriculture practiced in Romania is largely polluting, and the pollution phenomenon is largely known by Environmental specialists. The main aspects of environmental pollution caused by agricultural activities can be summarized in:

-Use of chemical fertilizers (especially with nitrogen) at doses too high and attimes uncorrelated with consumption in different stages of development of cultivated plants. Often, they are applied on the frozen ground and with a thick layer of snow, and by the sudden melting and favored by the slope of the land, they come through washing in the running waters used as sources of drinking water.

-Application of chemicals (pesticides) to combat diseases, insects, rodents and weeds from agricultural crops and plantations of trees and vines by poorly trained people. Applying some amounts and concentrations too much at unsuitable times and using products with high toxicity and long-term remanence has multiple negative effects on plants, animals and humans. It is also very important the aspect related to the preparation of pesticide solutions, the washing and discharging of the remaining solutions from the agricultural equipments used in their administration.

-Degradation of the physical state of soils (structure, porosity, permeability, plow resistance) as a result of the decrease of the organic matter content and the exaggerated traffic on the land with agricultural machinery, at an inadequate soil moisture.

-Uncontrolled storage of manure from private household animals have a negative effect on leakage into the running water and nitrate infestation of groundwater. 
-Evacuation of wastewater, untreated or incompletely treated from industrial livestock farming systems in surface water. To this is added the infiltration of wastewater in depth, affecting the quality of groundwater used as a source of drinking water supply in many rural localities.

-Use on agricultural land for the purpose of fertilization and irrigation, sludge and wastewater from livestock farmers, containing harmful salts and pathogens contaminating soil, plants, animals and humans.

In conclusion, intensive farming that uses large amounts of pesticides affects the environment. Irrational land use has effects such as soil degradation and the loss of important cropland areas. Soil pollution, water pollution, habitat fragmentation and loss of wildlife are often the consequences of inappropriate agricultural practices, and man should take into account the environmental effects it produces.

One requirement of good agricultural practice is that each agricultural producer to apply recommendations on how to use different types of chemical or organic fertilizers and to knows very well their conditions and periods of application. This knowledge, along with the correct assessment of the amount of nitrate in the soil, allows the farmer to optimize the ratio between the costs borne for the fertilizers and the value of the production obtained under environmental protection.

It is considered as a good agricultural practice to adapt the fertilization and its timing to the type of crop and the soil properties. Nutrient needs assessment is based on the soil nutrient reserve, local climatic conditions, and the quantity and quality of forecast production.

Because of the specific nitrogen behavior in the soil, fertilization with this nutrient and the culture techniques that influence its dynamics in the soil must be made in a manner that limits the losses with water that percolates, thus reducing the risk of contamination of groundwater and surface waters.

It is important to be aware of the high level of manure fertilization. If they are rich in nutrients, it is compulsory and cost-efficient for farmers to store and use them at the expense of mineral fertilizers, which are less accessible due to high prices. This organic fertilizer is inexpensive and at the reach of every farmer, and in addition it can be supplemented with chemical fertilizers to achieve the optimal nutrient requirement for agricultural crops, depending on the potential of the soil.

The European Union through the Common Agricultural Policy promotes sustainable agriculture. But because of the growth of the population, the increase in the need for food, agriculture will face a major challenge in the coming years: to provide food for the growing population, but not to pollute the environment.

\section{References}

1.ALMASRI, M. N., KALUARACHCHI, J. J. (2004). Assessment and management of long-term nitrate pollution of ground water in agriculture-dominated watersheds. J ournal of Hydrology, 295(1), 225245.

2.ALLOWAY, B., AYRES, D. C. (1997). Chemical principles of environmental pollution. CRC press.

3.ARSIC S., MIJ AJLOVIC N., KLJAJIC N. 2013, Organic Production and Its Role in Environmental Protection, Scientific Papers. Series Management, Economic Engineering in Agriculture and rural development, Vol. 13 ISSUE 3, PRINT ISSN 2284-7995, 17-24.

4.BOCK, B. R., HERGERT, G. W. (1991). Fertilizer nitrogen management. Managing nitrogen for groundwater quality and farm profitability, 139164.

5.BOYD, C. E., MASSAUT, L. (1999). Risks associated with the use of chemicals in pond aquaculture. Aquacultural Engineering, 20(2), 113132.
6.GARDNER, K. K., \& VOGEL, R. M. (2005), Predicting groundwater nitrate concentration from land use. Ground Water Journal, 43, 343352

7.HART, M. R., QUIN, B. F., \& NGUYEN, M. (2004), Phosphorus runoff from agricultural land and direct fertilizer effects. Journal of Environmental Quality, 33(6), 1954-1972.

8.LAKE, D. L., KIRK, P. W. W., \& LESTER, J. N. (1984), Fractionation, characterization, and speciation of heavy metals in sewage sludge and sludge-amended soils: a review. J ournal of environmental quality, 13(2), 175-183.

9.LERNER, D. N., \& HARRIS, B. (2009). The relationship between land use and groundwater resources and quality. Land Use Policy, 26S, S265-S273

10.MAHVI, A. H., NOURI, J., BABAEI, A. A., \& NABIZADEH, R. (2005). Agricultural activities impact on groundwater nitrate pollution. International J ournal of Environmental Science and Technology (IJEST), Vol. 2, No. 1, pp. 41-47

11.MIHALACHE M., ILIE L., MARIN D. I. (2015), Romanian soil resources - healthy soils for a healthy life. Scientific Papers. Series AgroLife J ournal, Vol. 4 ISSUE 1, PRINT ISSN 2285-5718, 101-110.

12.MOCUTA, D., Influence of the Climate Changes on the Human Life Quality, in Rural Areas, Rev. Chim. (Bucharest), 68, no. 6, 2017, p. 1490-1494

13.MOCUTA D., (2016), Influenta dezvoltarii durabile asupra calitatii vietii, Editura Ceres, Bucuresti, ISBN 978-973-40-1115-5.

14.NEAGU C. (2013), Sources Of Eutrophication Of The Waters In Calarasi County. Scientific Papers. Series Management, Economic Engineering in Agriculture and rural development, Vol. 13 ISSUE 1, ISSN 2284-7995, 257-262.

15.ONDER MUSTAFA, CEYHAN ERCAN, KAHRAMAN ALI (2011), Effects of Agricultural Practices on Environment, International Conference on Biology, Environment and Chemistry IPCBEE vol. 24, 28-32.

16.RUSU T., BOGDAN I., MARIN D. I., MORARU PAULA IOANA, POP A. I., DUDA B. M. (2015), Effect of conservation agriculture on yield and protecting environmental resources. Scientific Papers. Series AgroLife Journal, Vol. 4 ISSUE 1, PRINT ISSN 2285-5718, 141-145.

17.SARB G. S., MATEDOC T., MATEDOC SIRB N., DUMA-COPCEA A., GRAD I., SUSTER G. (2013), Study Considering The Environmental Protection And Life Quality In Romania In The Context Of Sustainable Development. Scientific Papers. Series Management, Economic Engineering in Agriculture and rural development, Vol. 13 ISSUE 3, PRINT ISSN 2284-7995, 257-262.

18.SCHMIDT A., SMEDESCU D., MACK G., FINTINERU G. (2017), Is There a Nitrogen Deficit In Romanian Agriculture? AgroLife Scientific Journal, Volume 6, Number 1, ISSN 2285-5718, 243-248.

19.SERPIL SAVCI (2012), An Agricultural Pollutant: Chemical Fertilizer, International Journal of Environmental Science and Development, Vol. 3, No. 1, 73

20.SHAVIV, A., MIKKELSEN, R.L. (1993), Controlled-release fertilizers to increase efficiency of nutrient use and minimize environmental degradation - A review, Fertilizer Research J ournal, Volume 35, Issue 1-2, pp 1-12

21.SHEHRAWAT P. S., SINDHU N., DEVI P. (2015), Agricultural Waste Awareness and Utilization for Healthy Environment and Sustainable Livelihood. Scientific Papers. Series Management, Economic Engineering in Agriculture and rural development, Vol. 15 Issue 2, PRINT ISSN 2284-7995, pg. 371-376.

22.SINGH R.P., AGRAWAL M. (2008), Potential benefits and risks of land application of sewage sludge, Waste Management] ournal, Volume 28, Issue 2, 347-358.

23.SPALDING, R. F., \& EXNER M. E. (1993), Occurrence of Nitrate in Groundwater - A Review. J ournal of Environmental Quality, Vol. 22 No. 3, p. 392-402

24.UNGUREANU, G., IGNAT, G., VINTU, C. R., DIACONU, C. D., SANDU, I. G., Study of Utilization of Agricultural Waste as Environmental Issue in Romania, Rev. Chim. (Bucharest), 68, no. 3, 2017, p. 570-575

Manuscript received: 2.08 .2018 